\title{
ERRATUM
}

\section{Cryostratigraphy of mid-Miocene permafrost at Friis Hills, McMurdo Dry Valleys of Antarctica - ERRATUM}

\author{
M. VERRET, W. DICKINSON, D. LACELLE, D. FISHER, K. NORTON, H. CHORLEY, R. LEVY and T. NAISH
}

https://doi.org/10.1017/S0954102020000619, Published by Cambridge University Press, 16 December 2020

Key words: ground ice, Miocene Climatic Optimum, soluble ions, stable upland zone, stable water Isotopes, Erratum

Cambridge apologises for a publisher-introduced error during the production process of the above article (Verret, 2020).

Figure 2 was mistakenly positioned at two locations, figure 2 and figure 6. This Erratum contains the correct versions of these figures along with their captions.

\section{Reference}

Verret, M, et al. 2020. Cryostratigraphy of mid-Miocene permafrost at Friis Hills, McMurdo Dry Valleys of Antarctica. https://doi.org/10. 1017/S0954102020000619 


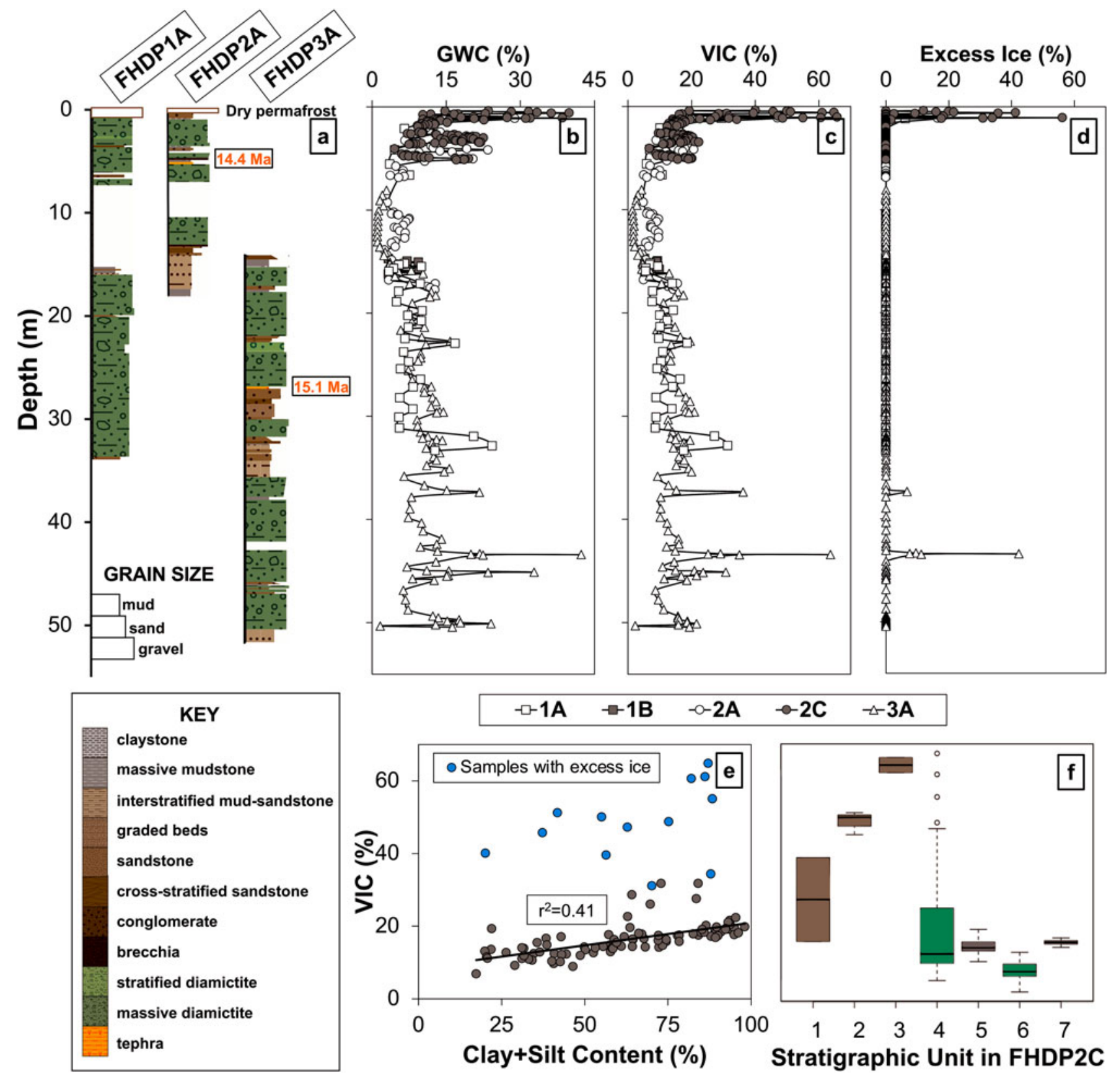

Fig. 2. a. General stratigraphy of Friis Hills Drilling Project (FHDP) cores FHDP1A, 2A and 3A with tephra ages provided by Hemming S. Cox (personal communication 2020). b.-d. Gravimetric water content (GWC), volumetric ice content (VIC) and excess ice content, respectively in the five FHDP cores. e. Relation between VIC and clay + silt content in FHDP2C. f. Boxplots of the VIC for the various stratigraphic units in FHDP2C. 

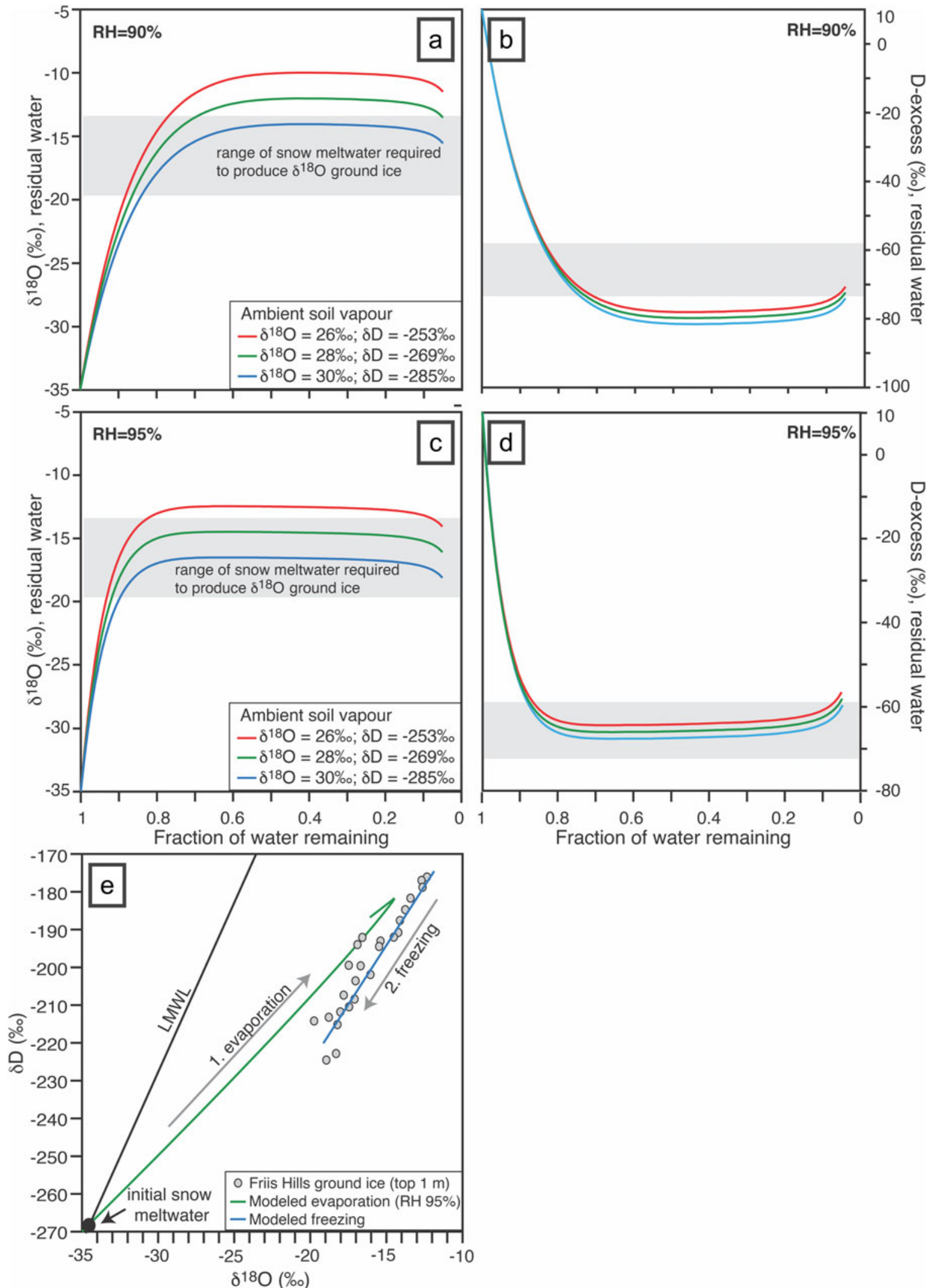

Fig. 6. Evolution of (a. \& c.) $\delta^{18} \mathrm{O}$ and (b. \& d.) D-excess for two scenarios of relative humidity (RH) (a. \& b.) of $90 \%$ and (c. \& d.) $95 \%$ for a range of soil water vapour values using a combination of the Craig et al. (1963) and Craig (1965) models for isotope exchange of evaporating water with ambient soil moisture and the isotope salt effect correction of Sofer \& Gat (1975). e. At the end of the evaporative evolution, the liquid water $\delta^{18} \mathrm{O}$ and $\delta \mathrm{D}$ are used to determine the first formed ice isotopic composition at the ice table. Note, for example, the liquid water's $\delta^{18} \mathrm{O}$ at the ice table is $\sim-15 \%$, so the first ice formed at the ice table would be $\sim-12 \%$ and would progressively decrease with depth following the freezing of the residual water. $\mathrm{LMWL}=$ local meteoric water line. 